\title{
A Cascade Quadruple Fly-boost for High Voltage Applications
}

\author{
Rathdharshagorn Suriyakulnaayudhya ${ }^{+}$ \\ Department of Electrical Engineering and Computer, Faculty of Science and Engineering,
}

Kasetsart University, Thailand. 47000.

\begin{abstract}
This paper proposed an alternative configuration to produce a high voltage gain of boost converter composed of two stages of quadruple fly-boost converter. The low input DC voltage of $20 \mathrm{~V}$ boosted up by two-cascade boost converter with the same duty ratio of 0.5 provided the voltage output $40 \mathrm{~V}$ and $80 \mathrm{~V}$ respectively. During turn off, an energy stored in an inductor transferred to secondary winding with turn ratio of 3.1, provided the voltage across the inductor secondary winding and then multiplied with quadruple circuit. The total output voltage of the proposed converter was the combination of the voltage from three sections that was $800 \mathrm{~V}$. To verify this concept, the voltage gain limitation of conventional boost converter and an $800 \mathrm{~V} 100 \mathrm{~W}$ cascade quadruple fly-boost converter has been analyzed, designed, and tested. The resulted indicated the duty cycle of the proposed converter at full load was 0.59 . The efficiency of the proposed cascade quadruple fly-boost converter was $83.27 \%$ and a voltage regulation, controlled with close loop PWM of the proposed converter was $2.7 \%$ respectively.
\end{abstract}

Keywords: Boost converter, flyback converter, step-up power supply circuit, voltage multiplied

\section{Introduction}

The use of an energy conversion device has imposed severe demand for an energy crisis today in order to converse energy, produced from many types of renewable sources that trend is constantly growing. The boost converter is popular for many designers. However, even if the conventional boost converter can provide a high voltage gain by utilizing an extremely high duty cycle but it is too complicated to archives the voltage gain more than 10 because of an ESR of its inductor. With very high duty cycle, a nonlinear voltage characteristic occurs and difficult to regulate a high output voltage of converter. Thus, most of the conventional boost converter cannot realize high voltage step-up due to the narrow allowed duty cycle [1][5].

The low circuit efficiency, from which the high duty cycle operation for high voltage gain, can be improve with the cascade boost converter as shows in Fig.1. Although, circuit in Fig.1 offered a choice of design in order to acquire a high voltage gain of boost converter, operated on linear characteristic curve but it also did not cover many applications that require very high voltage. This paper would like to introduce an alternative method to archive a higher voltage gain with the basic configuration shows in Fig.2. There are two circuit sections in the proposed configuration to achieve high voltage gain ratio.

\footnotetext{
${ }^{+}$Corresponding author.

E-mail address: Rathdharshagorn.s@ku.ac.th.
} 


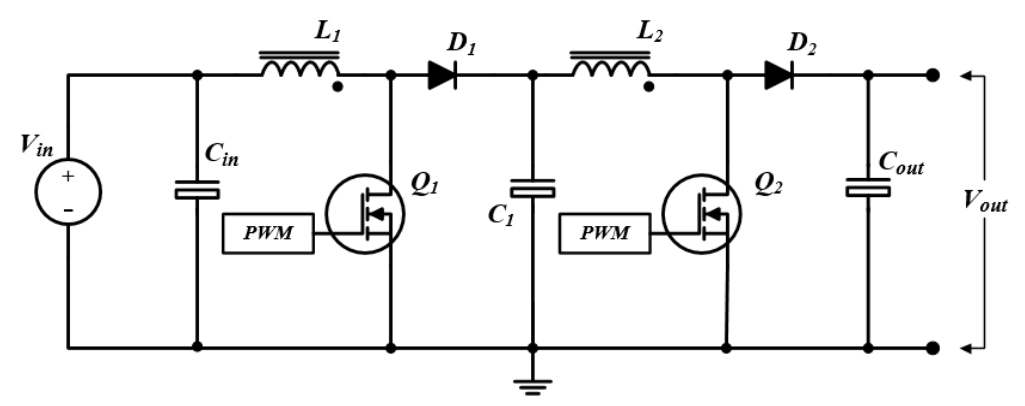

Fig.1: Circuit configuration of cascade boost converter.

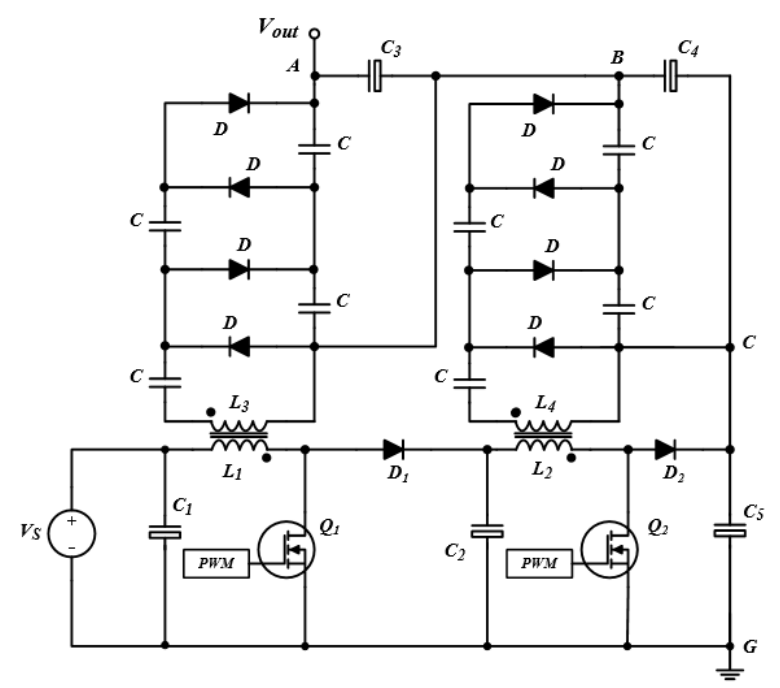

Fig.2: Circuit configuration of the proposed converter

\section{Proposed Circuit Analysis}

In this paper, basically, there are two main sections of the proposed converter circuit, boost section and quadruple fly-boost section, which can be explain in two parts below.

\subsection{Limitation of Boost Converter}

Fig. 3(a) illustrates the basic boost converter with load connected. For a steady state analysis, assuming the inductor's current and capacitor's voltage are constant, the energy across an inductor during each period is equal to zero and the voltage transfer function is

$$
\frac{V_{O}}{V_{S}}=\frac{1}{(1-D)}
$$

Ignore any losses to simplify the analysis; the power input is equal to an output power, then the inductor current express as [6]-[7]

$$
I_{L}=\frac{V_{O}}{(1-D) R_{O}}
$$

The boundary inductance and the optimal output capacitance for a desired ripple voltage of conventional boost converter is equal to [6] 


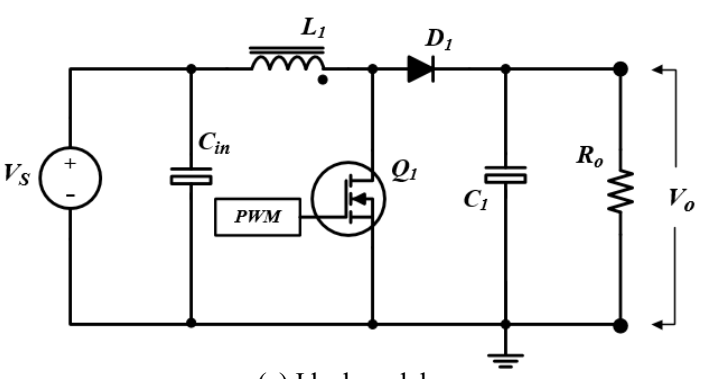

(a) Ideal model

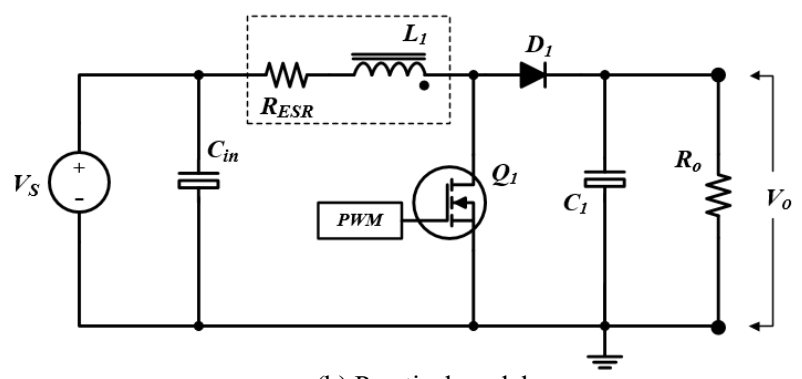

(b) Practical model

Fig.3: Boost configuration analysis

$$
\left.\begin{array}{c}
L_{B}=\frac{\left(1-D_{\min }\right)^{2} D_{\min } V_{O}}{2 f_{s w} I_{O(\min )}} \\
C_{O}=\frac{D_{\min } V_{O}}{R_{O} f_{s w} V_{r}}
\end{array}\right\}
$$

Where, $D_{\min }$ is the minimum duty cycle of the converter at the maximum input voltage and equal to

$$
D_{\min }=1-\left(\frac{\eta V_{S(\max )}}{V_{O}}\right)
$$

In practical designing, the ideal model of boost converter in Fig.3 (a) becomes the circuit in Fig.3 (b), the inductor's losses will be added through an equivalent series resistance or $R_{E S R}$, and we found

$$
0=\left(D\left(V_{S}-I_{L} R_{E S R}\right)\right)-\left((1-D)\left(V_{O}-V_{S}+I_{L} R_{E S R}\right)\right)
$$

Simplify Eq. (4) and substituting $I_{L}$ of Eq. (2) into Eq. (5), we get

$$
V_{S}=V_{O}\left\lfloor(1-D)+\frac{R_{E S R}}{(1-D) R_{O}}\right\rfloor
$$

Hence, the voltage transfer function becomes

$$
\frac{V_{O}}{V_{S}}=\frac{1}{(1-D)+\frac{R_{E S R}}{(1-D) R_{O}}}
$$

Eq. (7) clearly shown that the inductor's ESR will limit a voltage gain of conventional boost converter, especially for a duty cycle more than 0.75 . However, in order to stabilize the output voltage and easier to compensate the controller of the boost converter, the conventional boost converter, have to be operated in the linear region for each curve in Fig.4, which is in the range from 0 to 0.6 as shown in Fig.4. 


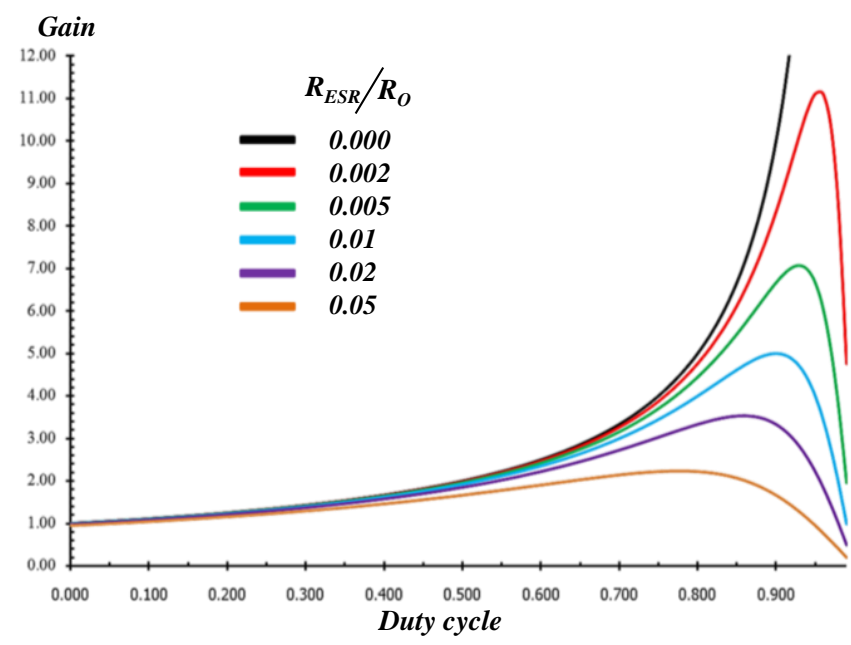

Fig.4: Voltage gain versus duty cycle

\subsection{A Proposed Converter Verification}

In an attempt to verify, a proposed converter of the limitation analyses mentioned above, a prototype of the cascade quadruple fly-boost converter as shown in Fig.2 is described as follow.

For quadruple multiplied circuit, the value of each capacitor is equal to [7]-[9]

$$
C_{n}=\frac{4 I_{O}}{V_{A C . p e a k} \times f} \quad ; \quad V_{A C, \text { peak }}=V_{L, t_{\text {off }}}=\frac{T V_{S, \max } D_{\text {min }}}{t_{\text {off }}}
$$

The output voltages of three sections in previous analysis, A, B and C in Fig.2 have to combination together. Thus, a high voltage output of the proposed converter is equal to $V_{A B}+V_{B C}+V_{C G}$ and then

$$
V_{\text {out }}=\frac{V_{S}}{(1-D)^{2}}+\left[4 V_{A C, p e a k}-\frac{5.5 I_{O}}{f_{s w} C_{n}}\right]+\left[4 V_{A C, p e a k}-\frac{5.5 I_{O}}{f_{s w} C_{n}}\right]
$$

\section{An Experimental Verification}

The laboratory prototype of a high gain quadruple fly-boost converter, constructed with the key circuit parameters designed as follow: Converter power rating is $100 \mathrm{~W}$, Converter estimate efficiency is $80 \%$, Converter normal input voltage is $20 \mathrm{~V}$, Converter output voltage is $800 \mathrm{~V}$ and Converter switching frequency is $150 \mathrm{kHz}$. First, for the boost converter section, the duty ratio of both boost converter was set to 0.5 for a normal input voltage in order to operate in the linear curve region, which produces the output voltage of $1^{s t}$ and $2^{\text {nd }}$ boost converter from Eq.(1) is $40 \mathrm{~V}$ and $80 \mathrm{~V}$ respectively. The $150 \mathrm{kHz}$ switching frequency provide a period of $6.66 \mu \mathrm{S}$. The converter output inductor and capacitor for $200 \mathrm{mV}_{\mathrm{p}-\mathrm{p}}$ ripple voltage are $133 \mu \mathrm{H}$ and $2 \mu \mathrm{F}$ for the first boost converter and $266 \mu \mathrm{H}$ and $2 \mu \mathrm{F}$ for the second boost converter respectively. Peak voltage across $L_{1}$ and $L_{2}$ in Fig.2 from Eq.(8) is $20 \mathrm{~V}$ and $40 \mathrm{~V}$ respectively. The turn ratio of both inductors $\left(N_{P} / N_{S}\right)$ set to 3.1 and capacitor in each stage of quadruple circuit is set to $1 \mu \mathrm{F}$. The total output voltage from the proposed converter in this paper obtains from

$$
\begin{gathered}
V_{A B}=[4 \cdot 20 \cdot(3.1)]-\left[\frac{(5.5) \cdot(0.125)}{150 k \cdot 1 \mu}\right]=243.42 \mathrm{~V} ; V_{B C}=[4 \cdot 40 \cdot(3.1)]-\left[\frac{(5.5) \cdot(0.125)}{150 k \cdot 1 \mu}\right]=491.42 \mathrm{~V} \\
V_{C G}=\frac{20}{(1-0.5)^{2}}=80 \mathrm{~V} \quad \rightarrow \quad V_{\text {out }}=243.42+491.42+80=814.84 \mathrm{~V}
\end{gathered}
$$


In Fig. 5 represent the drain-source voltage of power switch and full load inductor current of the first and second boost converter at $150 \mathrm{kHz}$ respectively, resulted the duty cycle of the proposed converter at full load is 0.59 .
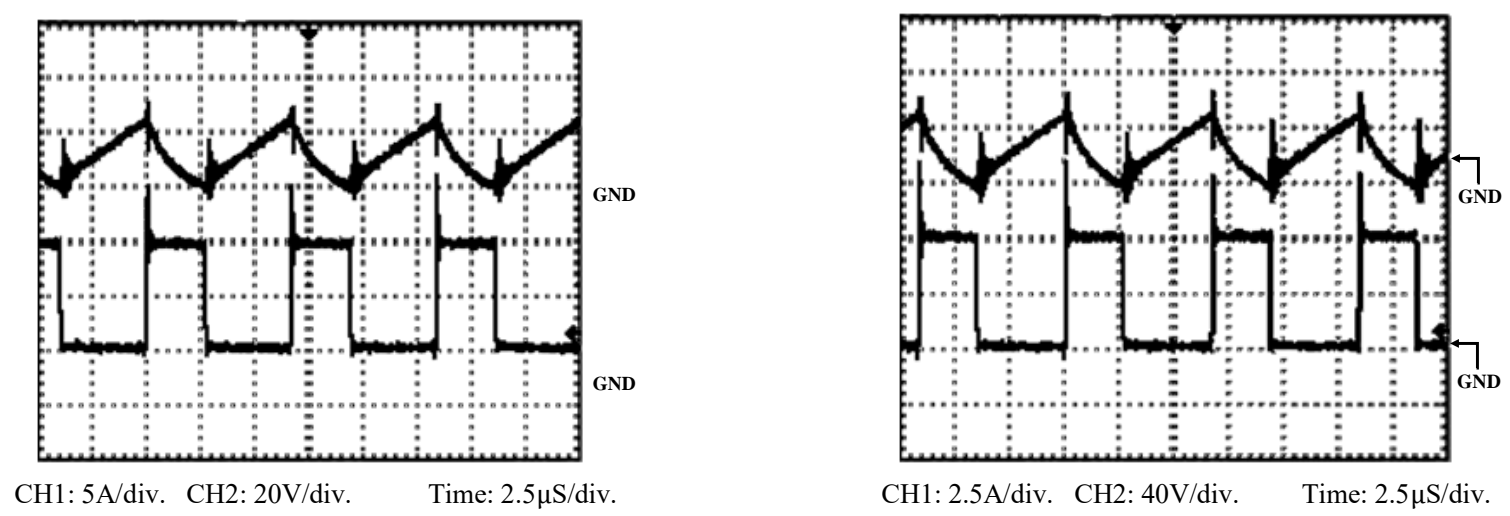

Fig.5: Top: Full load Inductor current, Bottom: $V_{d s}$ of $1^{\text {st }}$ and $2^{\text {nd }}$ boost converter.

The measurement of a time to steady state of the proposed converter for a high voltage output of $800 \mathrm{~V}$ shows in Fig.6 (a) with $100 \mathrm{mS} /$ div. Finally, Fig.6 (b) represent the measured of output voltage of the proposed converter versus the power output delivered to the load and efficiency of the converter versus the output power of the high gain cascade quadruple fly-boost converter circuit, proposed in this paper.

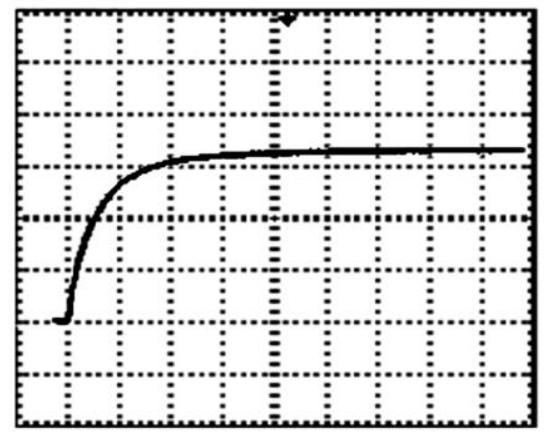

(a)

CH1: 250V/div. CH2: --.-- Time: $100 \mathrm{mS} / \mathrm{div}$.

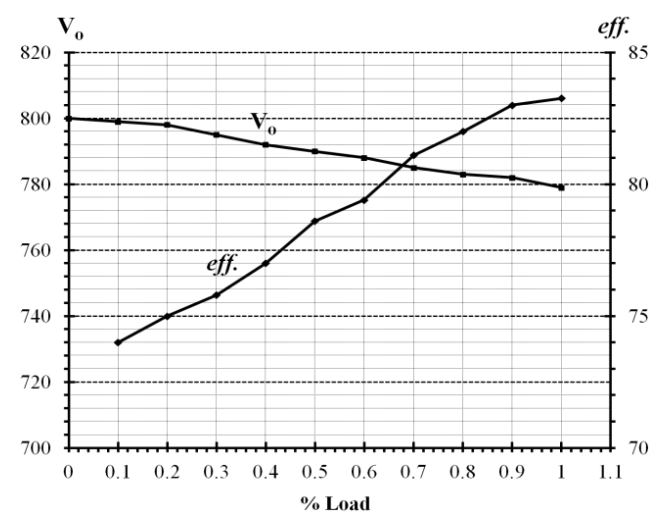

(b)

Fig.6: Time to steady state, output voltage and efficiency of the proposed converter

\section{Conclusion}

Base on a $20 \mathrm{~V}$ to $800 \mathrm{~V} 100 \mathrm{~W}$ prototype converter, experimental results demonstrate that the proposed cascade quadruple fly-boost converter provides a gain of 40 and the duty cycle of the proposed converter at full load is 0.59 that allows the converter operated in linear region $(\mathrm{D}<0.6)$. A time to complete for an output capacitor's charging of $800 \mathrm{~V}$ at no-load connected is $300 \mathrm{mS}$ as shows in Fig.6 (a). However, finally, the voltage regulation of the proposed cascade quadruple fly-boost converter, controlled by PWM technique is $2.7 \%$ and the maximum efficiency of the converter is $83.27 \%$ at full load.

In conclusions, an alternative method to provide the high gain step-up converter for high voltage high power applications, called cascade quadruple fly-boost converter, proposed, designed and tested in this paper. Results confirm that the proposed configuration, cascade quadruple fly-boost converter, is suitable for high voltage gain applications.

\section{References}

[1] F. Z. Peng, H. Li, G. J. Su and J. S. Lawler, “A New ZVS bidirectional DC-DC converter for Fuel cell and Battery application”, IEEE Trans. on Power Electronics, Vol.19, No.1, 2004, pp.54-65. 
[2] F. L. Luo, "Re-lift circuits: a new dc-dc step-up boost converter", IEE Proceedings-Electronics Letters, vol.33, no.1, 1997, pp.5-7.

[3] A. Reatti, “Low-cost high power-density electronic ballast for automotive HID lamp", IEEE Trans. on Power Electronics, Vol.15, No.2, 2000, pp.361-368.

[4] L. Baibi and R. Gules, "Isolated dc-dc converters with high-output voltage for TWTA telecommunication satellite applications", IEEE Trans. on Power Electronics, Vol.18, No.3, 2003, pp.975-984.

[5] Bor-Ren Lin, Chia-Hung Chao and Chih-Cheng Chien, "Interleaved Boost-Flyback Converter with Boundary Conduction Mode for Power Factor Correction", IEEE Conference on Industrial Electronics and Applications", 2011, pp.1828-1833.

[6] N. Mohan, W. P. Robbin and T. Undeland, "Power Electronics: Converter, Applications, and Design", Segunda Edition, New York Editorial, 1995.

[7] Julio C. Rosas-Caro, Juan M. Ramirez and Pedro Martin Garcia-Vite, "Novel DC-DC Multilevel Boost Converter", IEEE Xplore, 2008, pp.2146-2151.

[8] Priyen S. Patel and D.B. Dave, “Design, Analysis \&Implementation of Negative High Voltage DC Power Supply Using Voltage Multiplier Circuits”, International Journal of Engineering Trends and Technology (IJETT), Vol.4, Issue 4, April 2013, pp.702-706.

[9] Kwa-Sur Tam and Eric Bloodworth, “Automated Topological Generation and Analysis of Voltage Multiplier Circuits", IEEE Transaction on Circuits and Systems, Vol.31, No.3, March 1990. 